\title{
BIODEGRADABILIDAD DE RESIDUOS DE ALIMENTOS PREPARADOS BAJO CONDICIONES MESOFÍLICAS Y TERMOFÍLICAS UTILIZANDO UN REACTOR ANAERÓBICO DE MEZCLA COMPLETA
}

\author{
BIODEGRADABILITY OF PREPARED FOOD WASTE UNDER \\ MESOPHILIC AND THERMOPHILICS CONDITIONS USING A \\ COMPLETE MIX ANAEROBIC REACTOR
}

\author{
Maribet Rincón Ramírez', Nancy Rincón Lizardo², Joan Mata Álvarez³, Iván Chirinos ${ }^{4}$
}

Fecha de recepción: 2 de octubre de 2013

Fecha de aceptación: 31 de marzo de 2014

Referencia: M. Rincón Ramírez, N. Rincón Lizardo, J. Mata Álvarez, I. Chirinos. (2014). Biodegradabilidad de residuos de alimentos preparados bajo condiciones mesofilicas y termofilicas utilizando un reactor anaeróbico de mezcla completa. Ciencia e Ingeniería Neogranadina, 24 (1), pp. 29 - 48.

\section{RESUMEN}

En esta investigación se realizó la digestión anaeróbica de residuos de alimentos preparados (RAP) en un reactor anaeróbico de mezcla completa (RAMC) de 3,5 L, con flujo discontinuo bajo condiciones mesofílicas (CM) a $37{ }^{\circ} \mathrm{C}$ y termofílicas (CT) a $55^{\circ} \mathrm{C}$. El objetivo fue evaluar la biodegradabilidad de RAP con distintos lodos biológicos y tiempos de retención hidráulicos (TRH). Antes de la degradación, se realizó un ensayo de biodegradabilidad con diferentes proporciones de carbohidratos (C) frutas y vegetales (FV) y proteínas (P) en el que se obtuvo una mayor producción de biogás al trabajar con la proporción C:FV:P 24:71:5 en CM y CT. La misma se utilizó en el RAMC con TRH de 30, 25 y 15 d en CM y CT. Para la CM se obtuvieron remociones en ST de $59 \%$ y $67 \%$, SV de $76 \%$ y $81 \%$ para los $\mathrm{TRH}$ de 30 y $25 \mathrm{~d}$, con producciones de metano de 0,64 L/gSV removido y 0,31 L/gSV removido. Durante el TRH de 15 d se registró una inestabilidad debido a concentraciones de CO2 del $60 \%$. Durante la CT (TRH de 30 d) se removieron $67 \%$ de ST, $80 \%$ de SV y se registraron producciones de metano de 0,58 L/gSV removido. Cuando se implementó el TRH de 25 d se incrementaron los ácidos grasos volátiles hasta $2916 \mathrm{mg} / \mathrm{L}$ y se detuvo el tratamiento. Las mejores remociones y producción de biogás se generaron durante el TRH de 30 d en CM con el lodo EFLUENTE CACHAZA.

\footnotetext{
1. Ingeniero Civil, Doctora en Ingeniería Ambiental, mzrincon@fa.luz.edu.ve, Departamento de Ingeniería Suelos y Agua, Facultad de Agronomía, La Universidad del Zulia, Maracaibo, Estado Zulia, Venezuela.

2. Ingeniero Civil, Doctora en Ingeniería de Procesos y de Ambiente, nrincon@fing.luz.edu.ve, Departamento de Ingeniería Sanitaria y Ambiental, Facultad de Ingeniería, Escuela de Civil, La Universidad del Zulia, Maracaibo, Estado Zulia, Venezuela. 3. Ingeniero Químico, Doctor en Química, jmata@ub.edu, Departamento de Ingeniería Química, Universidad de Barcelona, Barcelona, España.

4. Ingeniero Agrónomo, MSc en Suelos y Nutrición de Plantas, ichirinos@fa.luz.edu.ve, Departamento de Ingeniería Suelos y Agua, Facultad de Agronomía, La Universidad del Zulia, Maracaibo, Estado Zulia, Venezuela.
} 
UNIVERSIDAD MILITAR NUEVA GRANADA - CIENCIA E INGENIERÍA NEOGRANADINA

Palabras clave: reactor anaeróbico, residuos de alimentos, biodegradabilidad.

\section{ABSTRACT}

This research examined the anaerobic digestion of prepared food waste (PFW) in a complete mix anaerobic reactor (CMAR) with a useful volume of $3.5 \mathrm{~L}$, with discontinuous flow under mesophilic conditions (MC) at $37^{\circ} \mathrm{C}$ and thermophilic conditions (TC) at $55^{\circ} \mathrm{C}$. Its objective was to evaluate the biodegradability of PFW with different biological sludge and hydraulic retention times (HRT). Prior to degradation, a biodegradability test was performed with different proportions of carbohydrates (C), fruits and vegetables (FV), and proteins (P). This test showed that the highest production of biogas was obtained by working with the proportion C:FV:P 24:71:5 in MC and TC. This proportion was digested in the CMAR with HRT of 30, 25 and 15 days in MC and TC. For the MC, ST removals of $59 \%$ and 67 $\%$ were obtained, and VS removals of $76 \%$ and $81 \%$ were obtained for 30 and 25 daysHRT, with methane yields of $0.64 \mathrm{~L} / g V S_{\text {removed }}$ and $0.31 \mathrm{~L} / g V S_{\text {removed. }}$ In the 15 day-HRT, an instability was registered due to CO2 concentrations of $60 \%$. During the TC (30 daysHRT), $67 \%$ of TS were removed, $80 \%$ of VS were removed, and methane yields of $0.58 \mathrm{~L}$ / gVSremoved were recorded. When the 25-days HRT was applied, the VFA increased until $2916 \mathrm{mg} / \mathrm{L}$ and the treatment was stopped. The best removals and biogas production were generated during the HRT of $30 \mathrm{~d}$ in MC with CACHAZA EFFLUENT sludge.

Keywords: anaerobic reactor, food waste, biodegradability.

\section{INTRODUCCIÓN}

La mayoría de los digestores anaeróbicos en Europa, fueron iniciados y operados bajo condiciones mesofílicas [1]. Sin embargo, suele aceptarse que, en condiciones termofílicasseobtienenmayoresactividades metabólicas, y mejores resultados. Además, las tasas de conversión del sustrato por los microorganismos termofílicos se reflejan en tasas de producción de metano más altas. Esto hace que se puedan disminuir los tiempos de retención en el digestor y así tratar mayores volúmenes de residuos [2]. También se incrementa la velocidad de crecimiento de los microorganismos, que puede llegar a ser dos o tres veces superior a la de los microorganismos mesófilos [3].
La operación en condiciones termofílicas está experimentando un renacimiento debido a la preocupación pública sobre los impactos potencialmente negativos de los agentes patógenos y contaminantes de biosólidos sobre el medio ambiente y al creciente interés en la energía renovable [4]. La necesidad de reducir las emisiones de gases de efecto invernadero, especialmente de dióxido de carbono, y de desarrollar una alternativa confiable a los combustibles fósiles ha llevado a un aumento de la atención a las energías renovables.

La generación y manejo de los residuos sólidos ha sido siempre un problema de orden ambiental, agudo y generalizado, que se presenta en la gran mayoría de las 
ciudades del mundo, habiéndose estimado que la producción de estos residuos por habitante ha sido desde el año 1960 de $1 \mathrm{~kg} / \mathrm{d}$ y hasta el $2010 \mathrm{de} 2 \mathrm{~kg} / \mathrm{d}$ [5]. Los residuos sólidos municipales contienen una fracción orgánica biodegradable superior al $40 \%$ y el manejo convencional ha sido principalmente la disposición en rellenos sanitarios [6].

Las fracciones orgánicas de los residuos domésticos contienen una alta proporción de nutrientes, que una vez estabilizados pudieran ser utilizados como abono en el suelo. De esta manera, se permitiría el mejoramiento de la fertilidad de éste, cuyas continuas pérdidas de nutrientes suelen ser compensadas con la adición de fertilizantes generalmente de origen mineral. Sin embargo, las fracciones orgánicas de los residuos domésticos han sido generalmente tratadas como contaminantes.

Las formas iónicas preferentes de absorción de nitrógeno por las raíces de las plantas son el nitrato $\left(\mathrm{NO}_{3}{ }^{-}\right)$y el amonio $\left(\mathrm{NH}_{4}{ }^{+}\right)$ [7]. Éste último es generado durante la mineralización del nitrógeno orgánico en la digestión anaeróbica. Además se estarían aprovechando otras múltiples ventajas de este tipo de tratamiento, como lo son la reducción de sólidos y generación de metano.

Hoy en día, la digestión anaeróbica de los residuos de alimentos es un campo investigado intensamente. Muchas configuraciones anaeróbicas novedosas han sido desarrolladas y aplicadas para el tratamiento de los residuos de alimentos, tales como las de dos etapas o sistema anaeróbico híbrido sólido-líquido [8]. Debido a la complejidad y el alto costo de operación técnica, la mayoría de estos procesos están aún en escala piloto. En la aplicación práctica, el tratamiento de una sola fase es, por lo general, el más predominante y el que se aplica en todas las escalas [9].

Con miras a evaluar la biodegradabilidad de los residuos de alimentos preparados se ensayó la degradación anaeróbica de este sustrato bajo condiciones mesofílicas y termofílicas utilizando un reactor anaeróbico de mezcla completa.

\section{MATERIALES Y MÉTODOS}

Se utilizó un reactor anaeróbico de alta carga denominado en esta investigación como reactor anaeróbico de mezcla completa (RAMC), con un volumen útil de $3,5 \mathrm{~L}$, construido con un cilindro doble de vidrio (marca Trallero and Schlee). En el espacio entre las paredes del reactor circula el agua a las temperaturas de $37^{\circ} \mathrm{C}$ o $55^{\circ} \mathrm{C}$, según sea la condición a ensayar, mesofílica o termofílica, mediante un baño de circulación digital programable marca Digisystem. Este reactor está dotado de un sistema de agitación acoplado a un motor de 0,05 HP que impide la incrustación de materia en las paredes, lo que garantiza la mezcla completa, y su desempeño se evaluó a una velocidad rotacional de aproximadamente 130 rpm. El reactor es monofásico, es decir, el tiempo de retención hidráulico (TRH) y el tiempo de retención celular $(\theta \mathrm{c})$ son iguales. Un esquema ilustrativo del reactor se presenta en la Figura 1. 
Para la determinación del mejor TRH existente. La condición de estabilización se establecieron tres tratamientos: el se alcanzó cuando los coeficientes de tratamiento $T_{1}$ a 30 días, $T_{2}$ a 25 días y $T_{3}$ variación en las determinaciones de $S T$ a 15 días. Se inició el ensayo con el $T_{1}$ y los (sólidos totales) y SV (sólidos volátiles) en el TRH se disminuyeron sólo cuando se obtuvo efluente resultaron menores al 10 \%. la estabilización para la condición de carga

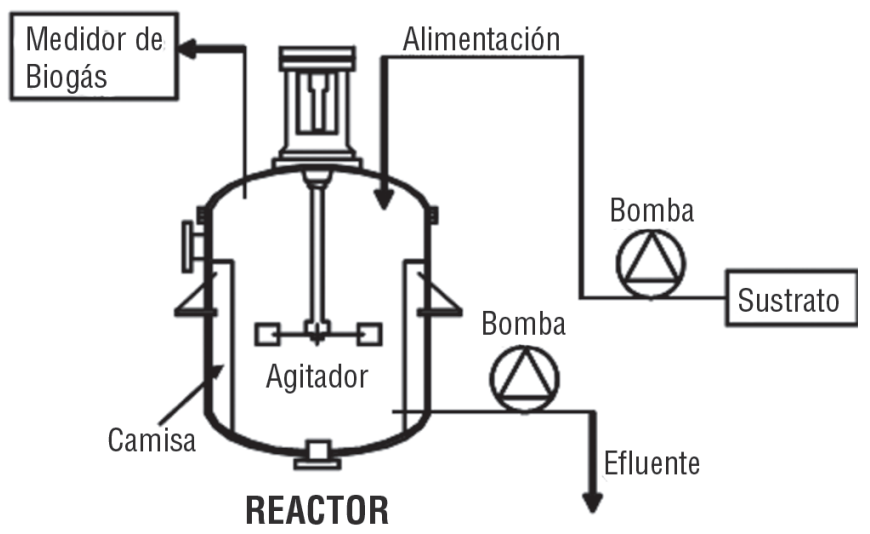

Figura 1. Esquema ilustrativo del reactor.

Durante la condición mesofílica (CM), se durantelos primeros días de la investigación utilizó como inóculo el lodo obtenido del se le agregaba glucosa para probar la efluente anaeróbico mesofilico para la actividad del inóculo (en una proporción degradación de un sustrato de cachaza $1 \mathrm{~g} / \mathrm{L})$, NaHCO3 (0,5 g/L) y nutrientes. En que se denominará en adelante en esta la Tabla 1 se muestran las condiciones investigación EFLUENTE CACHAZA diluido operacionales impuestas al RAMC durante hasta 22 g/L con agua destilada, a la cual, toda la experimentación.

Tabla 1. Condiciones operacionales impuestas al RAMC para la degradación de los RAP.

\begin{tabular}{|lccc|}
\hline \multicolumn{1}{|c}{ Lodo inóculo } & Temperatura & TRH & $\begin{array}{c}\text { Tiempo } \\
\text { (d) }\end{array}$ \\
\hline EFLUENTE CACHAZA & $37^{\circ} \mathrm{C}$ & 30 & $0-46$ \\
& $37^{\circ} \mathrm{C}$ & 25 & $47-78$ \\
EFLUENTE MESOFÍLICO RAP & $37^{\circ} \mathrm{C}$ & 15 & $79-89$ \\
& $55^{\circ} \mathrm{C}$ & 30 & $90-102$ \\
& $55^{\circ} \mathrm{C}$ & 50 & $103-117$ \\
EFLUENTE RAP/CACHAZA & $55^{\circ} \mathrm{C}$ & 100 & $118-144$ \\
& $55^{\circ} \mathrm{C}$ & 100 & $145-168$ \\
& $55^{\circ} \mathrm{C}$ & 50 & $169-186$ \\
& $55^{\circ} \mathrm{C}$ & 30 & $187-218$ \\
& $55^{\circ} \mathrm{C}$ & 25 & $219-245$ \\
\hline
\end{tabular}


Para la condición termofílica (CT) se utilizaron dos inóculos: un lodo originado del tratamiento mesofílico de los RAP a un $\mathrm{TRH}=15 \mathrm{~d}$, que se denominará en adelante EFLUENTE MESOFÍlICO RAP; y un lodo que se originó durante el tratamiento de un sustrato que combinó RAP y CACHAZA, que se llamará en adelante EFLUENTE RAP/CACHAZA.

\subsection{PRUEBA DE BIODEGRADABILIDAD DEL SUSTRATO CON REACTORES POR CARGA}

Antes de la evaluación de la degradación anaeróbica de los RAP en el RAMC, se realizó una prueba de biodegradabilidad
(CM y CT), en la que se ensayaron diferentes proporciones de carbohidratos (C), frutas-vegetales (FV) y proteínas (P) con sólidos totales de $4 \%$, que fueron seleccionados de acuerdo a los alimentos de mayor consumo por los venezolanos según el Instituto Nacional de Estadística (INE). Adicionalmente se agregó el mango por ser una fruta de alto consumo en el estado Zulia. Las diferentes proporciones fueron preparadas en el laboratorio y preservadas en cavas a $4^{\circ} \mathrm{C}$. En la Tabla 2 se presentan las diferentes proporciones de alimentos utilizados.

Tabla 2. Diferentes proporciones de alimentos utilizados para la preparación del sustrato RAP durante la prueba de biodegradabilidad.

\begin{tabular}{|lccc|}
\hline & $\begin{array}{c}\text { Proporción } \\
\text { C:FV:P } \\
\text { 47,5:47,5:5 }\end{array}$ & $\begin{array}{c}\text { Proporción \% } \\
\text { C:FV:P }\end{array}$ & $\begin{array}{c}\text { Proporción \% } \\
\text { C:FV:P } \\
\text { 71:24:5 }\end{array}$ \\
\hline Pasta & 11 & 17 & $\mathbf{2 4 1 : 5}$ \\
Arroz & 11 & 17 & 6 \\
Pan & 11 & 17 & 5 \\
Harina maíz & 14,5 & 20 & 6 \\
Papa & & & 7 \\
Zanahoria & 15 & 7 & 23 \\
Plátano & 6 & 4 & 9 \\
Mango & 5 & 2 & 7 \\
Cambur & 15 & 7 & 23 \\
Carne & 6 & 4 & 9 \\
\hline
\end{tabular}

La biodegradabilidad de estos sustratos fue evaluada por triplicado mediante la producción de biogás, medido por el desplazamiento del agua, mezclando 100 $\mathrm{mL}$ de las proporciones C:FV:P, 47,5:47,5:5, 71:24:5 y 24:71:5 respectivamente con 20 $\mathrm{mL}$ del inóculo. La temperatura se mantuvo en $37^{\circ} \mathrm{C}$ para la CM y $55^{\circ} \mathrm{C}$ para la $\mathrm{CT}$ por medio de un baño de calentamiento. La respiración endógena se cuantificó en uno de los reactores sin la adición de fuente de carbono (20 mL inóculo y 100 mL agua destilada). Con la finalidad de ver la actividad del lodo, un reactor estuvo preparado 
con $1 \mathrm{~g}$ de glucosa, $20 \mathrm{~mL}$ del inóculo y $100 \mathrm{~mL}$ de agua destilada; sin embargo, el volumen de biogás desplazado en este reactor no puede compararse con los otros por contener distintas DQO totales. La mejor proporción de C:FV:P (RAP) fue preparada en el laboratorio, almacenada en envases de $5 \mathrm{~L}$ de capacidad y preservada en cavas a $4^{\circ} \mathrm{C}$ para alimentar el RAMC. La biodegradabilidad se midió por comparación del volumen de biogás desplazado por cada reactor luego de sustraído el volumen de biogás por actividad endógena.

\subsection{MEDICIÓN DE PARÁMETROS FÍSICO- QUIIMICOS}

Los parámetros a medir en cada tratamiento fueron: producción diaria del biogás (por desplazamiento del agua), el pH, ST, SV y la alcalinidad total. Éstos se midieron de acuerdo con las pautas de Standard Methods for the Examination of Water and Wastewater [10]. Los ácidos grasos volátiles (AGV) se determinaron mediante un cromatógrafo de gas Perkin Elmer modelo Autosystem XL con un Detector de lonización de Llama (FID) y una columna de Nukol 30 m. Como gas de arrastre se utilizó nitrógeno con un caudal de $35 \mathrm{~cm} / \mathrm{s}$ y temperaturas: en el horno, de $185^{\circ} \mathrm{C}$; en el inyector, de $220^{\circ} \mathrm{C}$; y en el FID, de 250 ${ }^{\circ} \mathrm{C}$. Las muestras de lodo se centrifugaron por cinco minutos y se filtraron utilizando un filtro de 0,20 $\mu \mathrm{m}$. Para acidificar la muestra se añadió $1 \mathrm{~mL}$ de ácido fórmico (1\%) por cada $10 \mathrm{~mL}$ de muestra, y se inyectaron $2 \mu \mathrm{L}$ en el cromatógrafo. La concentración de metano se midió a través de un cromatógrafo de gases Perkin Elmer modelo Autosystem XL con una columna empacada Hayesep D 100/120. Se acopló al sistema un Detector de Conductividad Térmica (TCD). La temperatura del horno se fijó en $35^{\circ} \mathrm{C}$ y la del inyector en $120^{\circ} \mathrm{C}$. Se usó hidrógeno como gas de arrastre a 40 $\mathrm{cm} / \mathrm{s}$, y se inyectó un volumen de $200 \mu \mathrm{L}$ en el puerto correspondiente al TCD.

La demanda química de oxígeno (DQO), el nitrógeno amoniacal (NA), nitrógeno Kjeldahl (NK) y fósforo disponible (P) se midieron al final de cada tratamiento una vez lograda la estabilización del digestor, de acuerdo al Standard Methods [10] y el P según Van Reeuwijk [11].

\section{RESULTADOS Y DISCUSION}

Antes de cargar el RAMC con los RAP, éstos debieron someterse a un pretratamiento mecánico para reducir el tamaño de las partículas y ser homogeneizados para facilitar la digestión; éstos también fueron diluidos a una concentración aproximada del $4 \%$ de ST para operar el RAMC. En la Tabla 3 se presenta la caracterización de los inóculos y los RAP, y cada valor corresponde a la media de tres observaciones. Los bajos valores de $\mathrm{pH}$ observados en los RAP hacen necesaria la incorporación de un agente amortiguador externo para evitar la acidificación en el sistema. La relación de SV/ST en los RAP para la CM y CT fue de 0,98 y 0,85 correspondiente a la cantidad de biomasa presente, lo que evidenció una alta proporción de biomasa en el sistema de tratamiento. 
Tabla 3. Caracterización de los diferentes inóculos y RAP utilizados en el RAMC.

\begin{tabular}{|c|c|c|c|c|c|}
\hline \multirow[b]{2}{*}{ Parámetros } & \multicolumn{2}{|c|}{ ONDICIÓN MESOFÍLICA } & \multicolumn{2}{|c|}{ CONDICIÓN TERMOFÍLICA } & \multirow[b]{2}{*}{ RAP } \\
\hline & $\begin{array}{l}\text { Inóculo } \\
\text { EFLUENTE } \\
\text { CACHAZA }\end{array}$ & RAP & $\begin{array}{c}\text { Inóculo } \\
\text { EFLUENTE } \\
\text { MESOFILICO } \\
\text { RAP } \\
\end{array}$ & $\begin{array}{c}\text { Inóculo } \\
\text { EFLUENTE } \\
\text { RAP/CACHAZA }\end{array}$ & \\
\hline $\mathrm{pH}$ & $7,42 \pm 0,4$ & $3,51 \pm 0,2$ & $7,54 \pm 0,3$ & $7,28 \pm 0,4$ & $3,19 \pm 0,15$ \\
\hline $\begin{array}{l}\text { Alcalinidad total mg } \\
\mathrm{CaCO}_{3} / \mathrm{L}\end{array}$ & $4.717 \pm 210$ & 0 & $5.965 \pm 340$ & $2.507 \pm 220$ & 0 \\
\hline Sólidos totales $\mathrm{g} / \mathrm{L}$ & $31,94 \pm 0,9$ & $42,47 \pm 0,88$ & $12,47 \pm 2,05$ & $20,41 \pm 1,62$ & $36,68 \pm 1,29$ \\
\hline Sólidos volátiles g/L & $10,80 \pm 0,6$ & $41,60 \pm 0,74$ & $5,86 \pm 0,06$ & $10,13 \pm 0,63$ & $31,08 \pm 3,11$ \\
\hline $\mathrm{DQO}$ total $\mathrm{g} / \mathrm{L}$ & $10,18 \pm 0,7$ & $39,74 \pm 1,95$ & $10,00 \pm 2,0$ & $8,16 \pm 0,60$ & $48,66 \pm 2,14$ \\
\hline Nitrógeno total mg/L & $263 \pm 28,57$ & $1.075 \pm 76,03$ & $1.302 \pm 29,10$ & $551 \pm 51,97$ & $1.632 \pm 171,00$ \\
\hline $\begin{array}{l}\text { Nitrógeno amoniacal } \\
\mathrm{mg} / \mathrm{L}\end{array}$ & $16,80 \pm 0$ & $113,87 \pm 3,23$ & $341,60 \pm 0$ & $86,80 \pm 0$ & $81,20 \pm 11,88$ \\
\hline $\begin{array}{l}\text { Fósforo (OLSEN) } \\
\text { mg/L }\end{array}$ & $211 \pm 4,83$ & $28 \pm 0,56$ & $43 \pm 4,41$ & $81 \pm 3,95$ & $37 \pm 1,03$ \\
\hline $\begin{array}{l}\text { Ácidos grasos } \\
\text { volátiles mg/L }\end{array}$ & ND & $421 \pm 15$ & ND & ND & $1.409 \pm 84$ \\
\hline Metano \% & 72,14 & - & 30,0 & - & \\
\hline
\end{tabular}

Con referencia al contenido de nitrógeno y fósforo en relación con la materia orgánica (expresada como DQO) para el tratamiento anaeróbico se puede expresar DQO:N:P como 1.000:5:1 según Guerrero y Montalvo [12]. Este requerimiento de macronutrientes, cuando no fue totalmente otorgado por el mismo sustrato (RAP) (para el caso del fósforo), fue suplido por el lodo inóculo para ambas condiciones. El fósforo reportado en este estudio es el extraído por el método Olsen, medido como $\mathrm{H}_{2} \mathrm{PO}_{4}$

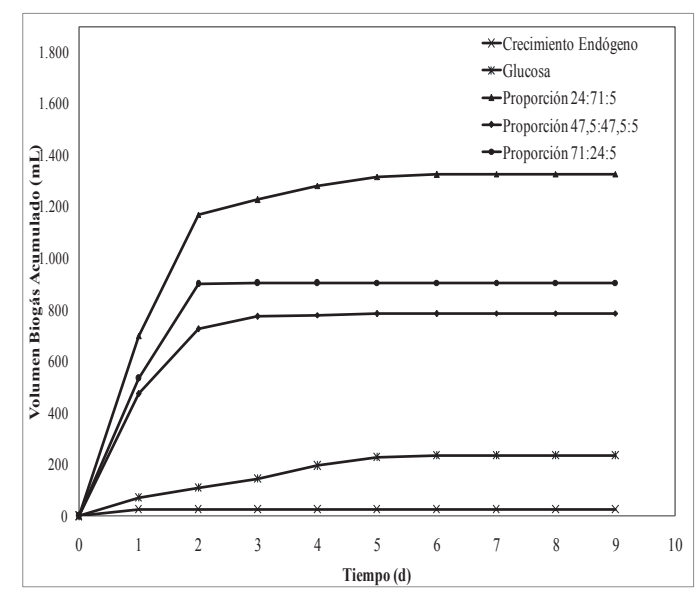

(a)

Figura 2. Evolución del volumen del biogás producido en el ensayo de biodegradabilidad de los RAP. (a) Condición mesofilica, (b) Condición termofilica y $\mathrm{HPO}_{4}{ }^{2-}$, las otras formas de fósforo no están contenidas en esta determinación.

\subsection{ENSAYO DE BIODEGRADABILIDAD BAJO CONDICIONES MESOFÍLICAS $Y$ TERMOFÍLICAS}

En la Figura 2 se muestra la evolución del volumen del biogás producido en el ensayo de biodegradabilidad. Para las CM y CT debió corregirse el $\mathrm{pH}$ a un valor cercano a 7 y al finalizar la prueba estos valores se encontraron cercanos a 5 unidades de $\mathrm{pH}$.

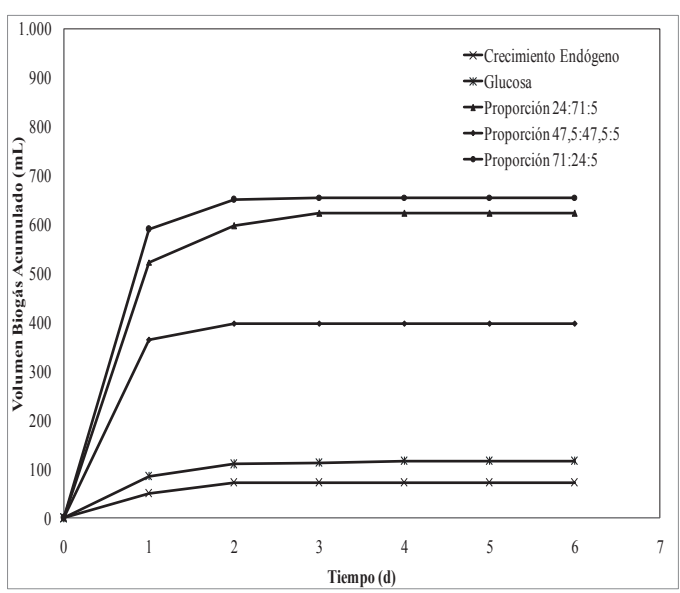

(b) 
Una vez aplicada la prueba en la CM, a los dos primeros días se observaron similares volúmenes de biogás en las proporciones C:FV:P 24:71 5 y 71:24:5. Sin embargo, a partir del tercer día y hasta alcanzar la estabilización, la proporción 24:71:5 generó un mayor volumen de biogás debido a que el tipo de carbohidrato presente en las frutas y vegetales es de tipo simple, como la fructosa y glucosa. También las vitaminas y minerales que conforman este grupo actúan como activadores de las reacciones de biodegradabilidad. Para el tercer día la proporción 24:71:5 había generado el $92 \%$ del biogás producido. Las frutas y vegetales también son ricos en celulosa, la cual sirve de sustrato a la biomasa para generar el biogás. En la Tabla 4 se muestra la medida de la actividad metanogénica en los reactores por carga y se aprecia que la proporción C:FV:P de 24:71:5 obtuvo una biodegradabilidad elevada. El reactor glucosa aportó una producción de biogás que permitió verificar la actividad de la biomasa seleccionada para inocular.

Tabla 4. Medida de la actividad metanogénica en los reactores por carga para diversas proporciones de los RAP en el ensayo de biodegradabilidad.

CONDICIÓN MESOFÍLICA

\begin{tabular}{|lcccc|}
\hline g SVagregado & 0,85 & 3,26 & 3,27 & 3,00 \\
mL de biogás acumulado & 209 & 1301 & 760 & 879 \\
mL biogás/gSVagregado & ND & 399 & 232 & 293 \\
CONDICIÓN TERMOFíLICA & & & & \\
g SVag & 0,86 & 3,50 & 3,62 & 3,76 \\
mL de biogás acumulado & 43 & 550 & 325 & 583 \\
$\mathrm{~mL}$ biogás/gSVagregado & $\mathrm{ND}$ & 157 & 90 & 155 \\
\hline
\end{tabular}

ND: No determinado

El sustrato con mejor producción de biogás (24:71:5) con 0,4 L biogás/ gSVagregado fue muy similar al resultado hallado por Elango et al. [13], quienes al degradar anaeróbicamente residuos sólidos municipales con lodos domésticos en reactores por carga bajo condiciones mesofílicas encontraron la máxima producción de biogás de 0,36 L/gSV agregado. Scaglione et al. [14] estabilizaron anaeróbicamente frutas y vegetales en reactores por carga mesofilica y obtuvieron

\section{Proporción de la RAP}

24:71:5 47,5:47,5:5 71:24:5

una producción de 0,79 L biogás/gSV agregado bajo condiciones normales, mientras que en este estudio la fracción con mayor contenido de frutas y vegetales alcanzó 0,4 L biogás/gSV agregado. Es importante destacar que el volumen de inóculo utilizado por Scaglione estuvo alrededor de $100-300 \mathrm{~mL}$ y $20 \mathrm{~mL}$ de sustrato.

La CT estuvo acompañada por menores producciones de biogás y se obtuvo la mayor producción durante el primer día 
con el 90 \% de la producción total de biogás. La proporción C:FV:P 71:24:5 superó solo en un $5 \%$ a la producción generada por la proporción C:FV:P 24:71:5 y ambas se mantuvieron alejadas de la proporción 47,5:47,5:5 en aproximadamente un $40 \%$.

La proporción C:FV:P 24:71:5 fue la seleccionada para el estudio de degradación anaeróbica en el RAMC, debido a que alcanzó la mayor producción de biogás/gSV agregado. $_{\text {. }}$ Estos resultados son inferiores a los presentados por Akunna et al. [15], quienes trabajaron con la digestión anaeróbica de residuos de comida a $55^{\circ} \mathrm{C}$ y después de siete días obtuvieron $492 \mathrm{~mL}$ biogás/ gSV $_{\text {agregado }}$ con 90 g de inóculo y sólo 10 g del sustrato para evitar la acumulación de AGV que podría inducir a una caída del pH. En este estudio, en contraste, solo se utilizaron $20 \mathrm{~mL}$ del inóculo y $100 \mathrm{~mL}$ del sustrato. Por esta razón se ha producido una acidificación parcial y, al elevar la temperatura a $55^{\circ} \mathrm{C}$, el nitrógeno posiblemente haya pasado a formas inhibidoras para la metanización.

\subsection{ALIMENTACIÓN DEL RAMC CON GLUCOSA. ETAPA DE ACLIMATACIÓN PARA LA CONDICIÓN MESOFÍLICA}

El lodo que sirvió como inóculo para la degradación de los RAP durante la CM fue EFLUENTE CACHAZA y la etapa de aclimatación se extendió por un período de $18 \mathrm{~d}$. Al final del mismo, se estaban produciendo por cada gramo de DQO removido $268 \mathrm{~mL}$ diarios de $\mathrm{CH}_{4}$ bajo condiciones normales, lo que evidenció la actividad del lodo biológico y permitió comenzar la alimentación con los RAP.

\subsection{ALIMENTACIÓN DEL RAMC CON GLUCOSA. ETAPA DE ACLIMATACIÓN PARA LA CONDICIÓN TERMOFÍLICA}

El primer inóculo utilizado para la degradación de los RAP en CT fue EFLUENTE MESOFILICO RAP. Este período abarcó 22 días y se obtuvieron $100 \mathrm{~mL} \mathrm{CH}_{4} / g$ de DQO removida bajo condiciones normales. Aun cuando este resultado estuvo muy por debajo del valor teórico de $350 \mathrm{~mL} \mathrm{CH} \mathrm{CH}_{4} / \mathrm{g}$ de DQO removida [16], se decidió comenzar con la alimentación de los RAP (TRH de 30 d) para ver si se lograba una mejoría aplicando los RAP a degradar.

El segundo inóculo utilizado para la degradación de los RAP bajo CT fue EFLUENTE RAP/CACHAZA al cual se le suministró glucosa y bicarbonato (1 g/L y $0,5 \mathrm{~g} / \mathrm{L})$ solo por dos días. Posteriormente se comenzó la alimentación con los RAP para un TRH de $100 \mathrm{~d}$.

\subsection{ALIMENTACIÓN DEL RAMC CON LOS RAP BAJO CONDICIONES MESOFÍLICAS Y TERMOFÍLICAS}

El tratamiento de los RAP en condiciones mesofílicas (CM) se llevó a cabo en un período de $89 \mathrm{~d}$, mientras que el tratamiento en condiciones termofílicas (CT) tomó 155 d.

\subsubsection{Parámetros de control $\mathrm{pH}$ y alcalinidad total}

Los valores de pH (entrada y salida) en el RAMC al degradar RAP se presentan en la Figura 3. En esta puede observarse que el $\mathrm{pH}$ para el influente (RAP) varió entre 
2,69 y 3,64 [17-18]. También se aprecia la estabilidad del reactor para el TRH de $30 \mathrm{~d}$ y $25 \mathrm{~d}$ correspondientes a la cargas orgánicas (CO) de 1,32 gSV/L.d y 1,55 gSV/L.d, dada la continua aplicación de una fuente buffer externa, la cual fue adicionada tres veces por semana en cantidades de 1,75 g.

El período de inestabilidad pudo constatarse al aplicar la CO de 2,8 gSV/L.d (TRH de 15 d), por lo que se decidió detener el tratamiento debido a que el contenido de $\mathrm{CO}_{2}$ en el sistema estuvo alrededor de $60 \%$ y en el rango de $\mathrm{pH}$ entre 6,0 y 7,5. La capacidad tampón del sistema es casi totalmente dependiente del sistema gas carbónico/ alcalinidad. La cantidad de ácido carbónico en solución está directamente relacionada con la cantidad de $\mathrm{CO}_{2}$ que se encuentra en la fase gaseosa [12].

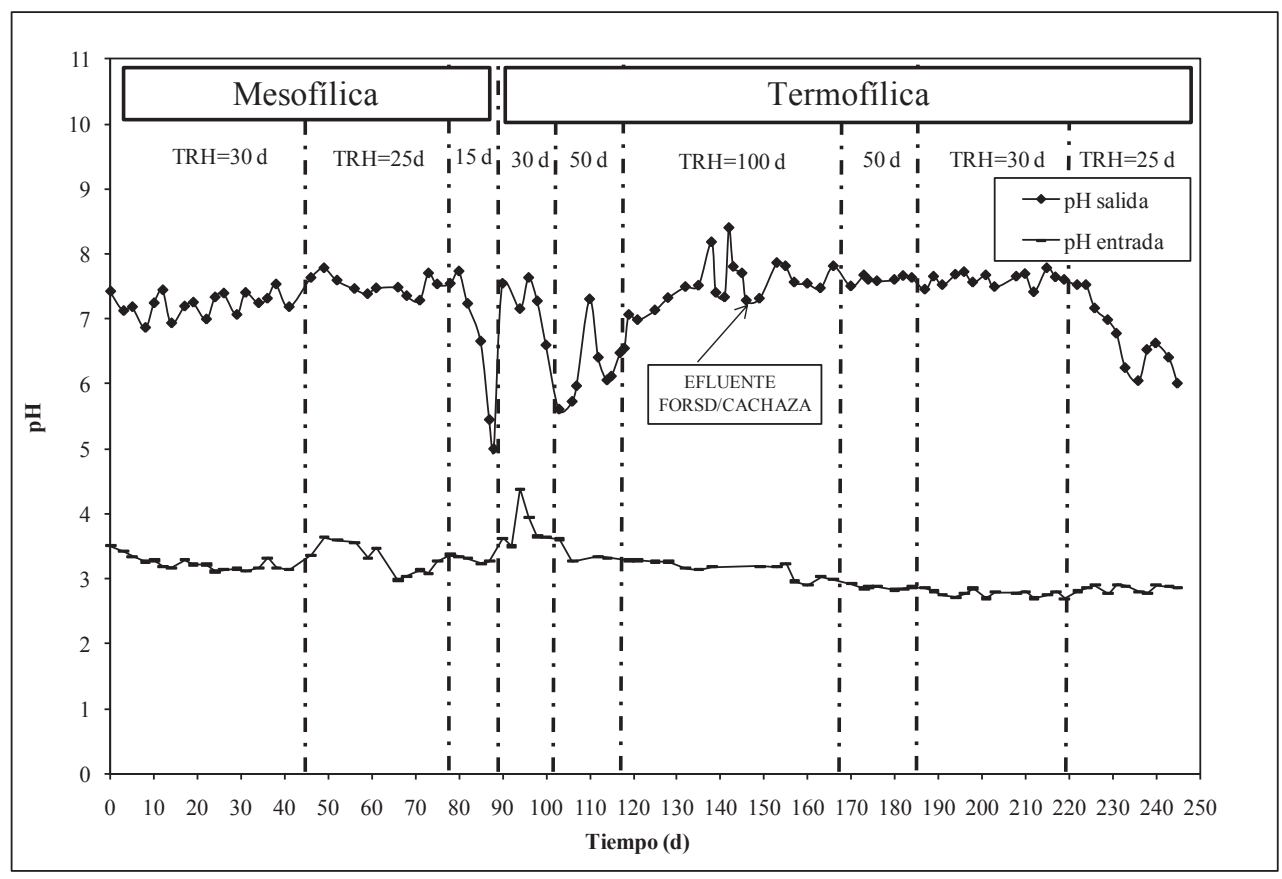

Figura 3. Variaciones del pH en el proceso de degradación de los RAP bajo condiciones mesofilicas y termofilicas.

Durante la CT (TRH de 30 d) hubo una caída de $\mathrm{pH}$ hasta 5,6, pese a la incorporación del $\mathrm{NaHCO}_{3}$. Por esta razón, se decidió bajar la carga orgánica aplicada a un TRH de 50 $\mathrm{d}$, en el que los valores de $\mathrm{pH}$ estuvieron por debajo de 6,5 aun cuando se llegaron a aplicar cantidades de hasta $5 \mathrm{~g}$ del $\mathrm{NaHCO}_{3}$. Habiendo reducido de nuevo la carga orgánica para un TRH de 100 d, se obtuvo una mejor respuesta en cuanto a esta variable. Sin embargo, otros parámetros como ST y SV presentaron un marcado 
ascenso, lo que evidenció la incapacidad del sistema para remover la materia orgánica.

El día 145 se extrajo todo el contenido del lodo dentro del RAMC y se agregó el inóculo EFLUENTE RAP/CACHAZA observándose un marcado equilibrio en los valores del $\mathrm{pH}$. Tres días después de haber cambiado el TRH a 25 d, comenzó a notarse el evidente descenso en esta variable, pese a la incorporación diaria del $\mathrm{NaHCO}_{3}$ en cantidades de 1, 2, 3, 4 y hasta $5 \mathrm{~g}$.

En la Figura 4, se muestran los valores de alcalinidad total (entrada y salida) en el RAMC. Al aplicar el TRH de 15 d (CM) se observó una fuerte caída en los valores de la alcalinidad, lo que corresponde a una condición de inestabilidad.
Una vez que se sustituyó el contenido del RAMC con el inóculo EFLUENTE RAP/ CACHAZA durante la CT se obtuvieron valores mucho más uniformes, que se prolongaron para el TRH de 50 d con la aplicación de 0,5 g del NaHCO3 tres veces a la semana. Sin embargo y al iniciar el TRH de 25 d, el sistema de tratamiento mostró una caída en los valores de la alcalinidad hasta $2091 \mathrm{mgCaCO}_{3} / \mathrm{L}$ y la progresiva recuperación de la misma a partir del día 230. Ésta última se debió a la incorporación del $\mathrm{NaHCO}_{3}$ diariamente y en dosis de 1 , 2, 3, 4 y hasta $5 \mathrm{~g}$, que fueron capaces de incrementar la alcalinidad pero no el pH, la producción de biogás y metano, por lo cual, se detuvo el tratamiento y no se aplicó el TRH menor (15 d).

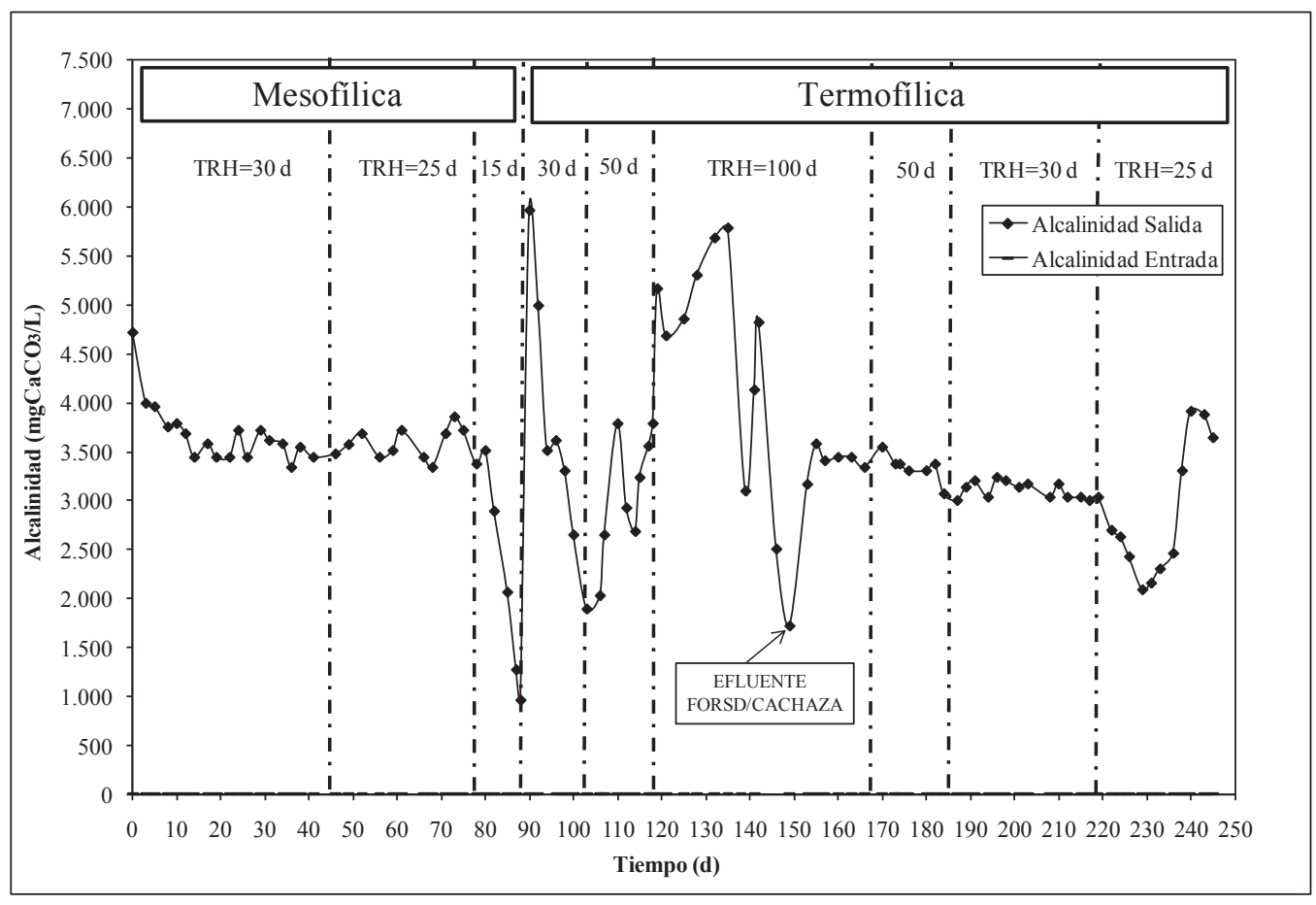

Figura 4. Valores de alcalinidad total (entrada y salida) en el RAMC al degradar RAP bajo condiciones mesofílicas y termofílicas. 


\subsubsection{Nitrógeno y fósforo}

El nitrógeno total determinado durante el período de estabilización para cada tratamiento realizado en CM permaneció con poca variabilidad. El contenido de nitrógeno y fósforo en las estabilizaciones para los diferentes TRH se indica en la Tabla 5.

El contenido de nitrógeno amoniacal para la CM experimentó variabilidad durante los distintos tratamientos. Igualmente, se encontraron fluctuaciones en los contenidos de nitrógeno amoniacal libre, que no superaron los $13 \mathrm{mg} / \mathrm{L}$.
El nitrógeno amoniacal se incrementó notablemente para el TRH de 30 d bajo la CT con respecto al contenido inicial presente en el inóculo EFLUENTE RAP/ CACHAZA $(81,20 \mathrm{mg} / \mathrm{L})$ pues llegó durante la estabilización del TRH de 30 d a 474,60 $\mathrm{mg} / \mathrm{L}$ y todos los parámetros de control como $\mathrm{pH}$ y alcalinidad se mantuvieron muy estables. Del mismo modo, se mostraron importantes remociones en la materia orgánica, acompañadas de una buena producción diaria de biogás y metano.

Tabla 5. Contenidos de nitrógeno y fósforo obtenidos en las estabilizaciones para los diferentes TRH en el RAMC al degradar RAP bajo condiciones termofilicas y mesofílicas.

\begin{tabular}{|cccccc|}
\hline $\begin{array}{c}\text { Carga } \\
\text { orgánica }\end{array}$ & $\begin{array}{c}\text { Temperatura } \\
\text { (g SV/L.d) }\end{array}$ & $\begin{array}{c}\text { TRH } \\
\text { (d) }\end{array}$ & $\begin{array}{c}\text { Nitrógeno } \\
\text { total } \\
\text { (mg/L) }\end{array}$ & $\begin{array}{c}\text { Nitrógeno } \\
\text { amoniacal } \\
\text { (mg/L) }\end{array}$ & $\begin{array}{c}\text { Fósforo Olsen } \\
\text { (mg/L) }\end{array}$ \\
1,32 & 37 & 30 & $1.015 \pm 38,01$ & $57 \pm 5,94$ & $79 \pm 4,30$ \\
1,55 & 37 & 25 & $958 \pm 29,18$ & $291 \pm 0$ & $69 \pm 3,70$ \\
2,80 & 37 & 15 & $963 \pm 15,20$ & $132 \pm 3,96$ & $38 \pm 1,70$ \\
1,07 & 55 & 30 & $956 \pm 103,84$ & $475 \pm 5,94$ & $25 \pm 4,86$ \\
1,26 & 55 & 25 & $1.544 \pm 0$ & $624 \pm 7,92$ & $50 \pm 1,53$ \\
\hline
\end{tabular}

Estos incrementos en el nitrógeno amoniacal se deben al aporte diario de los RAP y a la mineralización del nitrógeno total. Para el TRH de 25 d, el nitrógeno amoniacal se incrementó a $624 \mathrm{mg} / \mathrm{L}$. El contenido de nitrógeno amoniacal libre para el TRH de $30 \mathrm{~d}$ fue de $69 \mathrm{mg} / \mathrm{L}$ y para el TRH de 25 d fue de $5 \mathrm{mg} / \mathrm{L}$ debido a la disminución en el $\mathrm{pH}$. Tal y como puede apreciarse ninguno de estos valores superan los $100 \mathrm{mg} / \mathrm{L}$ considerados por Guerrero y Montalvo [12] como límite máximo para que se produzca la inhibición por nitrógeno amoniacal libre.

\subsubsection{Sólidos totales y volátiles}

En la Figura 5 se presenta la evolución de los sólidos totales y volátiles (entrada y salida) y en la Tabla 6 se observan las remociones de sólidos totales y volátiles para las diferentes estabilizaciones.

Una vez aplicado el TRH de 15 d, se observó el aumento de los ST y SV. Este incremento fue ocasionado por una condición de inestabilidad en el sistema. Sin embargo, la eliminación de los SV resultó similar a la encontrada por Bouallagui et al. [18], 
quienes trabajaron con la degradación anaeróbica mesofilica de vegetales y frutas con un $2,8 \%$ de ST en un reactor por carga de $2 \mathrm{~L}$ y 2,5 gSVag/L.d (TRH de 10 d). Estos investigadores obtuvieron una remoción de SV de $73,1 \pm 1,1 \%$, parecida a la reportada en este estudio para el TRH de $25 \mathrm{~d}$ con 1,55 gSVag/L.d.

Al iniciar la CT con el inóculo EFLUENTE MESOFÍlICO RAP, y una vez aclimatado a la temperatura de $55{ }^{\circ} \mathrm{C}$, se observó una acumulación en los ST y SV en el RAMC, razón por la cual, se procedió a aumentar los TRH a $50 \mathrm{~d}$ y luego a $100 \mathrm{~d}$. Durante el TRH de $100 \mathrm{~d}$ se siguió observando el incremento de los ST. Entonces se procedió a extraer todo el lodo del RAMC e inocular con el EFLUENTE RAP/CACHAZA, al cual se le fueron incrementando paulatinamente las cargas orgánicas, comenzando con un TRH de $100 \mathrm{~d}$, en el que se apreciaron, conforme a lo esperado, disminuciones en los ST y SV. Al cambiar al TRH de 50 d se siguió notando la adaptabilidad de la biomasa al incrementar la carga. La dificultad en la biodegradabilidad del sustrato RAP se debió a la condición de inestabilidad en la cual estuvo durante el TRH de 15 d para la CM, ya que al tratar de activar el lodo biológico utilizado, EFLUENTE MESOFÍLICO RAP, la producción de biogás fue baja en el momento del arranque, sólo $100 \mathrm{~mL}$ de biogás por gramo de glucosa aplicado. Esto indica que el reactor estaba en mal funcionamiento, no se había recuperado de la sobrecarga anterior y los datos de la siguiente carga estuvieron condicionados por ello.

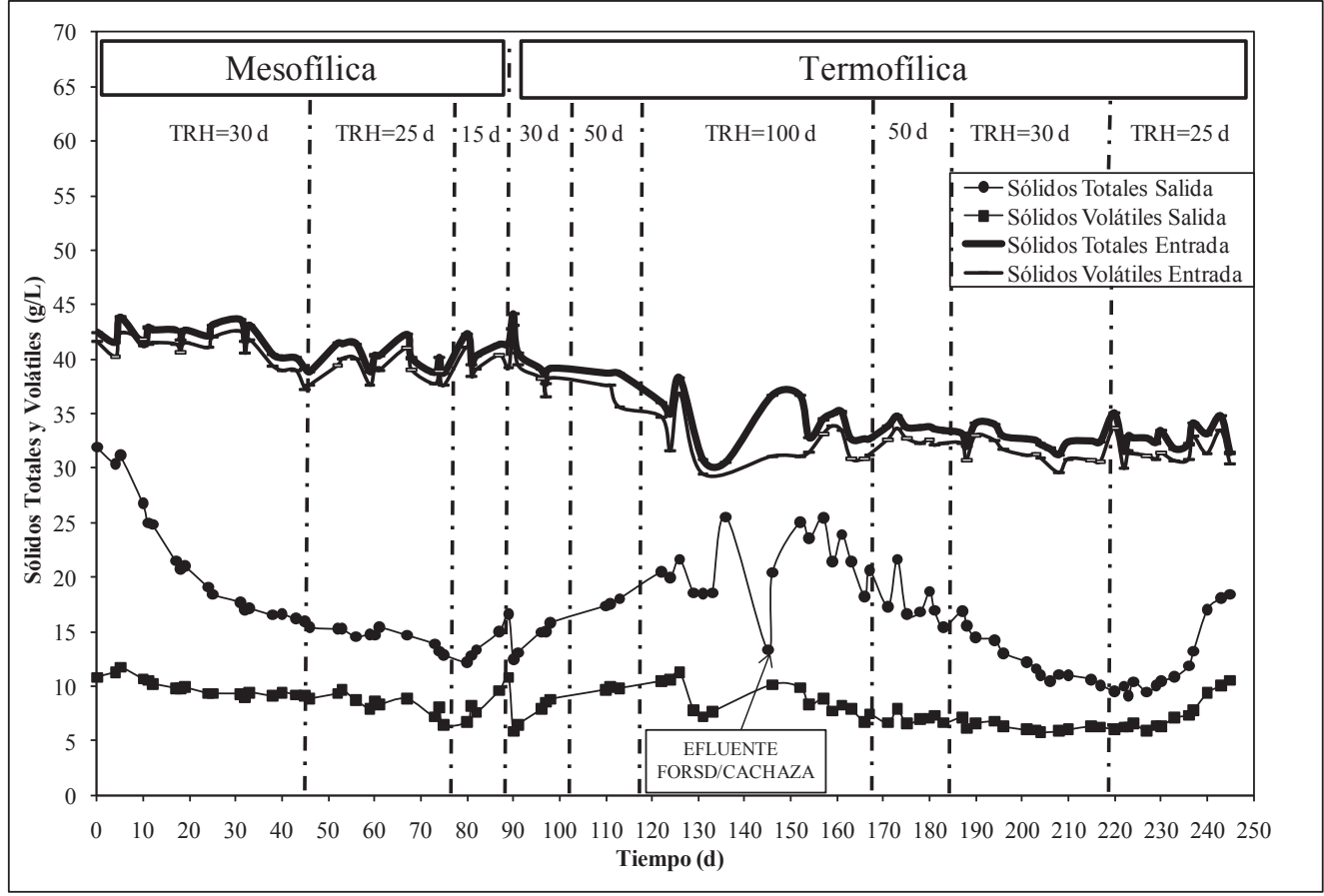

Figura 5. Evolución de los sólidos totales y volátiles (entrada y salida) en el RAMC al degradar RAP bajo condiciones mesofilicas y termofilicas. 
Tabla 6. Porcentajes de remoción de sólidos totales y volátiles para las diferentes estabilizaciones en el RAMC al degradar RAP bajo condiciones termofilicas y mesofilicas.

\begin{tabular}{|c|c|c|c|c|c|}
\hline \multicolumn{3}{|c|}{ \% Remoción sólidos totales } & \multicolumn{3}{|c|}{ \% Remoción sólidos volátiles } \\
\hline Me & lico & Termofílico & Mes & lico & Termofílico \\
\hline $\mathrm{TRH}=30 \mathrm{~d}$ & $\mathrm{TRH}=25 \mathrm{~d}$ & $\mathrm{TRH}=30 \mathrm{~d}$ & $\mathrm{TRH}=30 \mathrm{~d}$ & $\mathrm{TRH}=25 \mathrm{~d}$ & $\mathrm{TRH}=30 \mathrm{~d}$ \\
\hline $59 \pm 0,63$ & $67 \pm 2,67$ & $67 \pm 1,61$ & $76 \pm 0,78$ & $81 \pm 2,23$ & $80 \pm 0,76$ \\
\hline
\end{tabular}

Durante la aplicación del TRH de 30 d bajo $\mathrm{CT}$, los ST comenzaron a disminuir conforme a lo esperado hasta un valor inferior al obtenido con la misma carga orgánica bajo la CM y se reportó durante la estabilidad $10,65 \pm 0,4 \mathrm{~g} / \mathrm{L}$ de ST con remociones de 67 $\%$. Los SV se mantuvieron muy uniformes desde el TRH de $50 \mathrm{~d}$ y no presentaron fluctuaciones durante el TRH de $30 \mathrm{~d}$, en los que alcanzaron un valor de $6 \pm 0,24 \mathrm{~g} / \mathrm{L}$ en la estabilización con un $80 \%$ de remoción.

En este tipo de reactor en el que la digestión anaeróbica de los residuos de alimentos tiene lugar en una sola etapa pueden ocurrir inconvenientes cuando el sustrato es fácilmente degradable. Esto ha ocurrido al incrementar las cargas orgánicas porque en la digestión de residuos sólidos no hay posibilidad para la acumulación/retención de la biomasa dentro del reactor y el crecimiento de las bacterias metanogénicas es más lento al ser sobrealimentadas a cargas orgánicas más altas. De hecho, al utilizar el TRH de 25 d, después de 10 d de tratamiento los ST y SV comenzaron a incrementarse.
En CM al utilizar el lodo inóculo EFLUENTE CACHAZA, el sistema de tratamiento logró

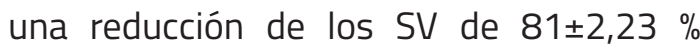
en la condición de TRH de 25 d, la mejor encontrada en estas condiciones. Para la CT, el lodo inóculo EFLUENTE MESOFILICO RAP que provenía de la condición mesofílica no logró activarse utilizando TRH desde 30 d a 100 d. Luego de ser sustituido por el lodo inóculo EFLUENTE RAP/CACHAZA, el sistema logró remover la materia orgánica y así se encontró su mejor funcionamiento para un TRH de 30 d con una remoción de $80 \pm 0,76 \%$ de SV.

\subsection{4. Ácidos grasos volátiles}

Los AGV representan un parámetro crítico en la operación y control de la digestión anaeróbica. En este estudio el reactor mostró una evolución típica que puede apreciarse en la Figura 6.

Al inicio del tratamiento se observó un contenido de AGV totales que llegó a ubicarse cerca de los $550 \mathrm{mg} / \mathrm{L}$, es decir, las fases de hidrólisis y acidogénesis 


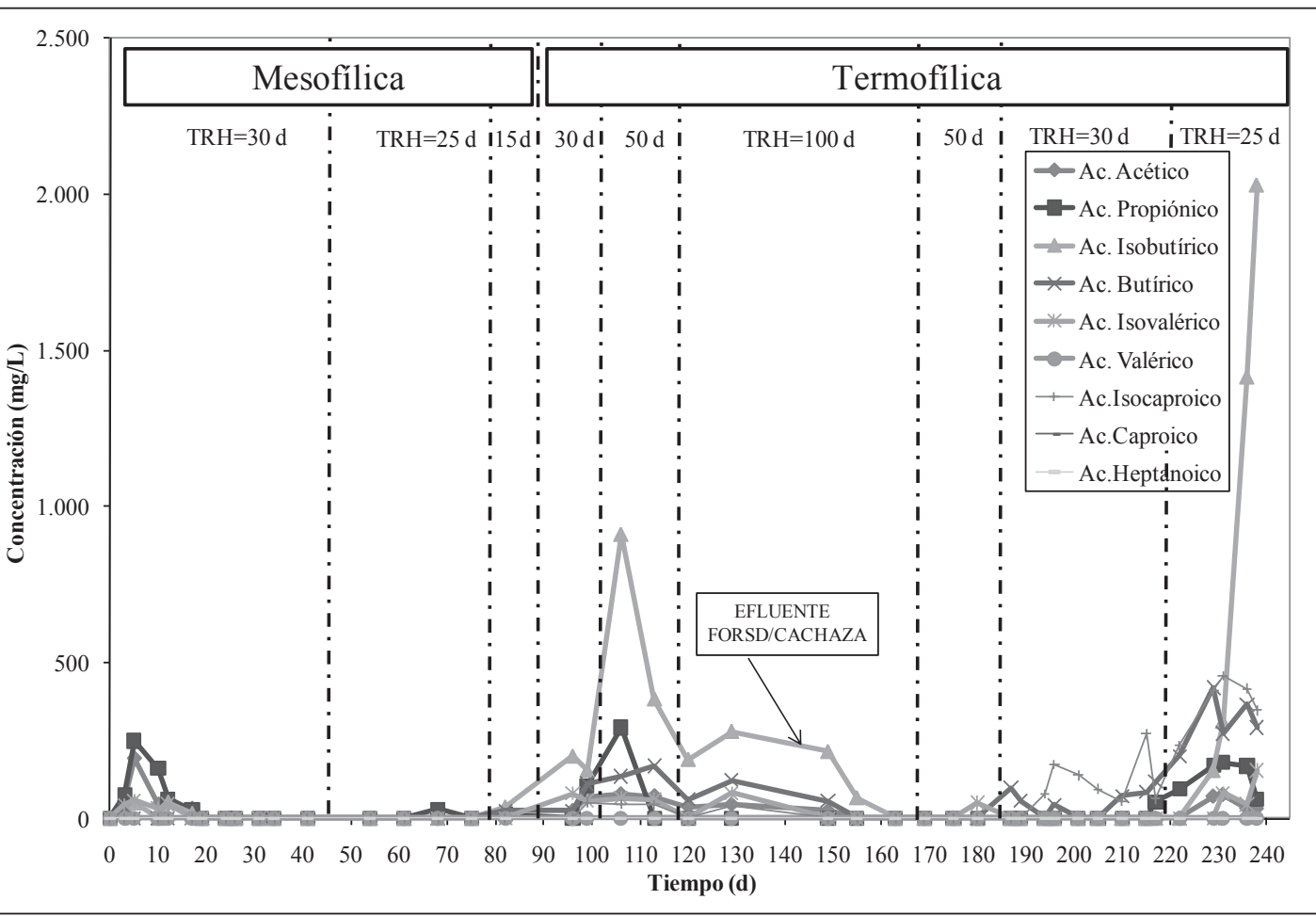

Figura 6. Evolución de los AGV a la salida del RAMC al degradar RAP bajo condiciones mesofilicas y termofílicas.

se observaron hasta el día 19, con una pequeña generación de AGV. Los ácidos detectados durante este período estuvieron representados principalmente por el acético y el propiónico. Después del día 20, y para el momento de la estabilización con el TRH de $30 \mathrm{~d}$, no llegaron a detectarse concentraciones de AGV, por lo que se presume que toda la materia orgánica hidrolizada fue transformada a metano, en relación con con el 76 \% de remoción encontrado en los SV.

El comportamiento inicial del reactor al degradar los RAP resultó similar al experimentado por Forster-Carneiro et al.
[19]. Al incrementar la carga orgánica a 1,55 g SV/L.d (TRH de 25 d), la producción de AGV se mantuvo muy escasa, lo cual se corresponde con la alta remoción de SV encontrados en este período (81\%). Al trabajar con la carga orgánica de 2,80 g SV/L.d ó TRH de 15 d se registraron incrementos de los AGV de 98 y 115 mg/L, constituidos por ácido propiónico, butírico e isobutírico, y una disminución en el porcentaje de remoción de los ST y SV.

Mohan y Bindhu [20], trabajaron con RAP en un digestor anaeróbico de una etapa y consiguieron incrementos en los contenidos de AGV, conforme incrementaban las 
cargas orgánicas, encontrando AGV de 2,07 g/L, 2,58 g/L, 3,88 g/L, 10,3 g/L para $1,5 \mathrm{~kg} \mathrm{SV} / \mathrm{m}^{3} \mathrm{~d}, 3,5 \mathrm{~kg} \mathrm{SV} / \mathrm{m}^{3} \mathrm{~d}, 4,5 \mathrm{~kg} \mathrm{SV} /$ $\mathrm{m}^{3} \mathrm{~d}$ y $5,5 \mathrm{~kg} S V / \mathrm{m}^{3} \mathrm{~d}$ respectivamente. Cuando la tasa de alimentación del sustrato fue incrementada, la actividad acidogénica se incrementó, mientras que la población metanogénica no pudo incrementar su actividad al mismo grado. Esto causó un desbalance desfavorable y considerables reducciones en la producción del metano, lo que redujo la eficiencia del reactor a cargas por encima de $4,5 \mathrm{~kg} \mathrm{SV} / \mathrm{m}^{3} \mathrm{~d}$.

Sin embargo, en este estudio bajo CM, aunque se trabajó con cargas orgánicas de $1,32,1,55$ y $2,8 \mathrm{~kg} \mathrm{SV} / \mathrm{m}^{3} \mathrm{~d}$ o TRH de 30,25 y 15 d respectivamente, no se llegó a detectar altas concentraciones de AGV. La inestabilidad reportada por la caída en el pH y la alcalinidad se debió a una alta concentración de $\mathrm{CO}_{2}$ en el sistema.

Al iniciar la CT con el inóculo EFLUENTE MESOFÍLICO RAP se observó la acumulación de acido isobutírico, propiónico, butírico, acético e isovalérico en el RAMC, los cuales disminuyeron hasta alrededor de $560 \mathrm{mg} / \mathrm{L}$ al disminuir las cargas orgánicas. Sin embargo, el lodo fue extraído del reactor debido a que no se lograba una recuperación del mismo en términos de remoción de ST y SV.

Después de inocular el RAMC con el EFLUENTE RAP/CACHAZA, el contenido de AGV disminuyó hasta valores no detectables para el TRH de 50 d y para el TRH de $30 \mathrm{~d}$ se obtuvieron AGV alrededor de $130 \mathrm{mg} / \mathrm{L}$. La concentración de estos AGV en el RAMC estuvo determinada por su tasa de producción y su tasa de remoción. En este caso, la tasa de remoción de estos ácidos fue superior a su tasa de producción correspondiéndose con una alta remoción en los SV (80 \%).

Finalmente, al utilizar el TRH de $25 \mathrm{~d}$ se observó el continuo ascenso de los AGV, en el que se destacó la presencia principalmente del isobutírico [21] y en menor proporción el isocaproico, butírico, propiónico y acético. El contenido de AGV totales llegó hasta 2916 $\mathrm{mg} / \mathrm{L}$ y el tratamiento debió detenerse en este punto debido a que este contenido de AGV estuvo acompañado por un descenso abrupto en el $\mathrm{pH}$, ya que se registraron concentraciones de $\mathrm{CO}_{2}$ por el orden de 67 \% razón por la cual, la remoción de los sólidos comenzó a decaer.

En general, la hidrólisis es la etapa limitante si el sustrato se encuentra en forma particulada. Sin embargo, la degradación anaeróbica de residuos pobres en celulosa, como este residuo que en su mayoría estuvo constituido por frutas y vegetales, está más limitada por la metanogénesis que por la hidrólisis [22]. Estos residuos son rápidamente acidificados a AGV y tienden a inhibir la metanogénesis cuando al sustrato no se le aplica adecuadamente un buffer o la carga orgánica es muy alta.

\subsubsection{Producción y composición del biogás}

La producción diaria de biogás en el RAMC al degradar RAP bajo condiciones mesofilicas y termofílicas es presentada en la Figura 7 , donde se muestran producciones al inicio del ensayo con una firme tendencia 
a incrementarse hasta obtener una estabilización por el orden de 3612 \pm 131 $\mathrm{mL} / \mathrm{d}$ para el TRH de $30 \mathrm{~d}$ (CM). Conforme se pasó al TRH de 25 d se incrementaron los volúmenes de biogás hasta el día 64, a partir del cual, se observó una caída de de la producción de biogás que se mantuvo en
$2504 \pm 64 \mathrm{~mL} / \mathrm{d}$. Una vez incrementada la carga orgánica hasta $3,5 \mathrm{~kg} \mathrm{DQO} / \mathrm{m}^{3} \mathrm{~d}(\mathrm{TRH}$ de 15 d) se experimentó una fuerte caída en las producciones de biogás, además de una inestabilidad general en el sistema de tratamiento con valores de $\mathrm{pH}$ menores a $5 \mathrm{y}$ alcalinidades inferiores a $1000 \mathrm{mg} / \mathrm{L} \mathrm{CaCO}_{3}$.

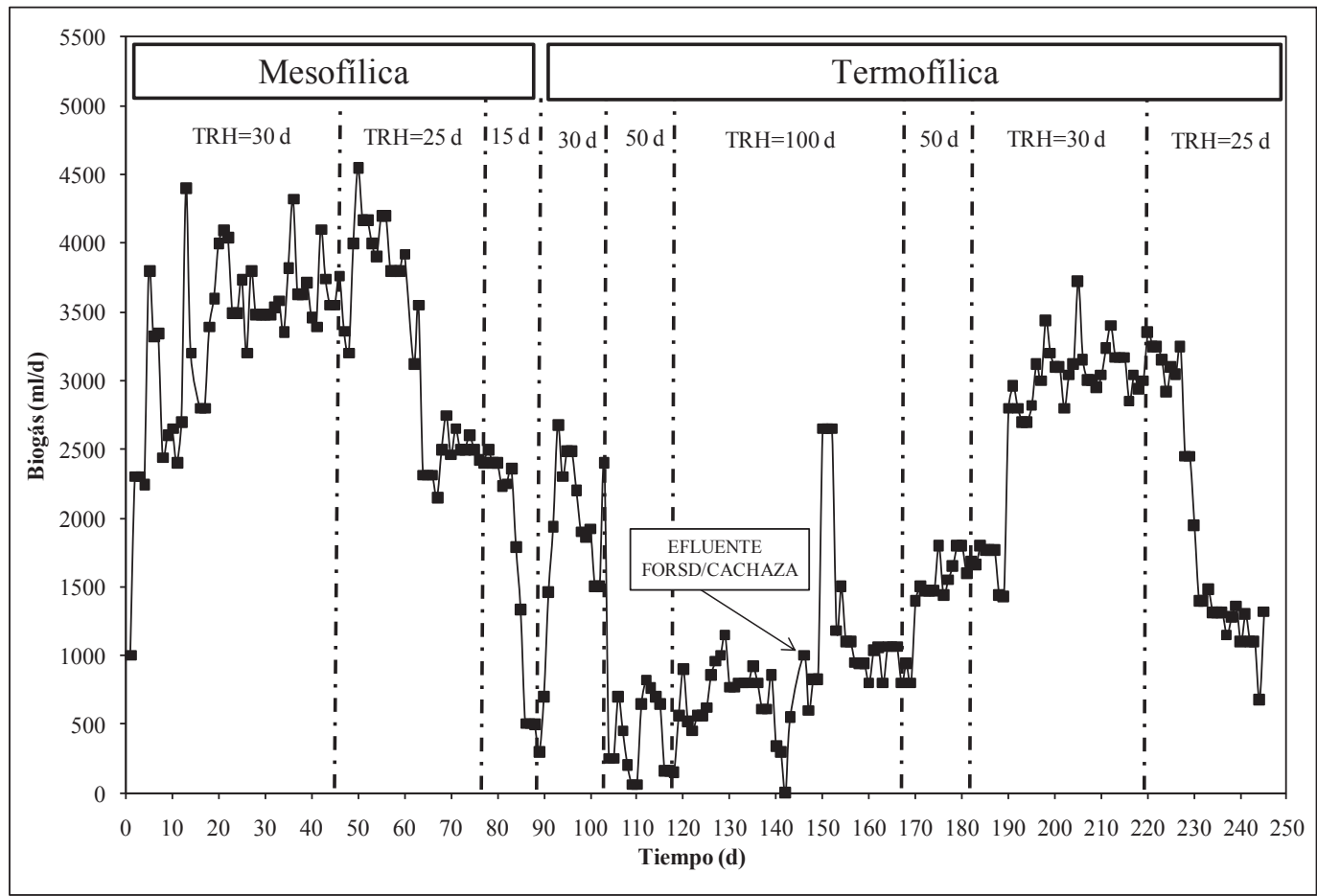

Figura 7. Producción diaria de biogás en el RAMC al degradar RAP bajo condiciones mesofilicas y termofilicas.

La producción de biogás para el TRH de 30 d durante la CT resultó en $3034 \pm 141 \mathrm{~mL} / \mathrm{d}$. a;Al incrementar la tasa de alimentación del sustrato (TRH de 25 d) aumentó la producciónde $A G V$, mientrasquelapoblación metanogénica no pudo incrementar su actividad a la misma medida, y se observó el descenso en la producción del biogás y el contenido de metano en éste.
Con referencia a la producción de metano en la Tabla 7 se muestra el comportamiento del RAMC referido a esta variable. El contenido de metano en CM (TRH de 30 d) resultó ser de $62,54 \%$ y 0,65 LCH4/L.d para el TRH de $30 \mathrm{~d}(1,32 \mathrm{gSV} / \mathrm{L} . \mathrm{d})$, y se relacionó con una alta remoción de materia orgánica, 76 \% de remoción de SV. 
UNIVERSIDAD MILITAR NUEVA GRANADA - CIENCIA E INGENIERÍA NEOGRANADINA

Tabla 7. Desempeño del RAMC referido a la producción de metano al degradar RAP bajo condiciones mesofilicas y termofílicas.

\begin{tabular}{|c|c|c|c|c|c|c|c|c|}
\hline Condición & $\begin{array}{l}\text { TRH } \\
\text { (d) }\end{array}$ & $\begin{array}{c}\text { CO } \\
\text { (gSV/L.d) }\end{array}$ & $\begin{array}{c}\text { Metano } \\
(\%)\end{array}$ & $\begin{array}{l}\text { Producción } \\
\text { diaria de } \\
\text { biogás } \\
\text { (L/d) }\end{array}$ & $\begin{array}{c}\text { Metano } \\
\text { (L/d) }\end{array}$ & $\begin{array}{l}\text { Metano } \\
\text { (L/L.d) }\end{array}$ & $\begin{array}{c}\text { Metano } \\
\text { (L/gSVagregado) }\end{array}$ & $\begin{array}{c}\text { Metano } \\
\text { (L/gSVremovido) }\end{array}$ \\
\hline Mesofílico & 30 & 1,32 & 62,54 & 3,612 & 2,26 & 0,65 & 0,49 & 0,64 \\
\hline Mesofílico & 25 & 1,55 & 54,10 & 2,504 & 1,35 & 0,39 & 0,25 & 0,31 \\
\hline Mesofílico & 15 & 2,80 & - & - & - & - & - & - \\
\hline Termofílico & 30 & 1,07 & 56,10 & 3,034 & 1,70 & 0,49 & 0,47 & 0,58 \\
\hline Termofílico & 25 & 1,26 & - & - & - & - & - & - \\
\hline
\end{tabular}

Las producciones de metano en CM resultaron superiores a la encontrada por Mohan y Bindhu [20], quienes para el tratamiento anaeróbico de los residuos domésticos en un reactor de $7 \mathrm{~L}$ bajo operación continua y 1,5 gSV/L.d hallaron producciones de metano durante el período de estabilización de 0,3 $\mathrm{LCH}_{4} /$ L.d.

La producción de biogás diaria resultó ligeramente superior durante la CM al compararlo con la CT para el mismo $\mathrm{TRH}$ de $30 \mathrm{~d}$, contrario a lo esperado y lo demostrado por Bouallagui et al. [17]. Ellos obtuvieron un $50 \%$ de incremento en la producción diaria de biogás bajo condiciones termofílicas al compararlo con la mesofílica, durante la degradación de residuos de frutas y vegetales en un reactor tubular de $18 \mathrm{~L}$ de volumen útil con un contenido de ST de $4 \%$. Mientras que el contenido de metano sí resultó mayor en la CM $(65 \%)$ que en la CT $(62 \%)$, esos contenidos resultaron muy similares a los presentados en este estudio.

La producción de biogás resultó superior a la encontrada por Gómez et al. [23]. Ellos, co-digestando lodo primario (LP) con la fracción frutal y vegetal de los residuos sólidos municipales (FFVRSM) bajo $C M$ en reactores de $3 \mathrm{~L}$, obtuvieron bajo condiciones normales de $1400 \mathrm{~mL} / \mathrm{d}$ para la carga de $4 \mathrm{gSV}_{\text {agregado}} / \mathrm{d}$. Ésta se asemejó más al TRH de 30 d en este estudio, cuya carga correspondería a 5

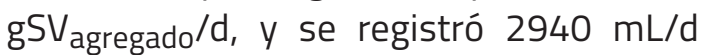
bajo condiciones normales.

La producción de metano alcanzada por Angelidaki et al. [21] fue menor a la obtenida en este estudio $\left(0,26 \mathrm{LCH}_{4}\right)$

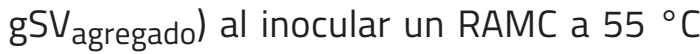
con el $10 \%$ de su volumen, alimentaron con Ios RAP licuados y diluidos a un contenido de ST de $6 \%, 3,73$ gSVagregado/d para un volumen de $3,5 \mathrm{~L}$.

\section{CONCLUSIONES}

Durante la prueba de biodegradabilidad la proporción que generó mayor producción de biogás en CM y CT fue la de mayor contenido de frutas y vegetales. Se obtuvieron las mayores producciones de biogás en la CM.

Se debe incrementar la relación inóculo/ sustratoen losensayos debiodegradabilidad para evitar la acumulación de ácidos, reducción en los valores del pH e inhibición de la actividad metanogénica. 
Pese a los distintos intentos de recuperación del inóculo, luego de una condición de inestabilidad en el sistema provocada por la aplicación del TRH de 15 d en CM, éste inóculo no pudo ser nuevamente activado.

Distintos lodos inóculos produjeron diferentes comportamientos en cuanto a remoción orgánica y a pesar de esperarse que la remoción fuese mayor en $\mathrm{CT}$, en este estudio el mejor TRH fue $30 \mathrm{~d}$ para la CM con el lodo inóculo EFLUENTE CACHAZA que alcanzó una remoción de $76 \%$ en los SV y una producción de metano de 0,64 L/gSV removido.

\section{REFERENCIAS}

[1] De Baere, L. (2000). Anaerobic digestion of solid waste: state-of-the art. Water Science and Technology, 41, pp. 283-290.

[2] Lu, J., Gavala, H., \& Skiadas, I. (2008). Improving anaerobic sewage sludge digestion by implementation of a hyperthermophilic prehydrolysis step. Journal of Environmental Management, 88, pp. 881-889.

[3] De la Rubia, M., Pérez, M., Romero, L., \& Sales, D. (2001). Digestión anaerobia termofílica versus digestión anaerobia mesofílica de lodos de EDAR. Residuos, 11(62), pp. 64-68.

[4] Lloret, E., Pastor, L., Pradas, P., \& Pascual, J. (2013). Semi full-scale thermophilic anaerobic digestion (TAnD) for advanced treatment of sewage sludge: Stabilization process and pathogen reduction. Chemical Engineering Journal, 232, pp. 42-50.
[5] Environment Protection Agency (EPA). (2010). Municipal solid waste in the United States: 2009 Facts and figures EPA530-R-10-012. Washington, D.C. EE.UU., p. 198.

[6] Sosnowski, P., Wieczorek, S., \& Ledakowicz. (2003). Anaerobic codigestion of sewage sludge and organic fraction of municipal solid wastes. Advances in Environmental Research, 7, pp. 609-616.

[7] Azcón, B. \& Talón, M. (2000). Fundamentos de Fisiología Vegetal (Primera Edición). Madrid, España: McGraw Hill. P. 522.

[8] Zhanga, L., Ouyanga, W. \& Lia, A. (2012). Essential role of trace elements in continuous anaerobic digestion of food waste. Procedia Environmental Sciences, 16, pp. 102-111.

[9] Li, R., Chen, S, \& Li, X. (2010). Biogas production from anaerobic co-digestion of food waste with dairy manure in a two-phase digestion system. Appl Biochem Biotechnol, 160, pp. 643-654.

[10] American Public Health Association (APHA). American Water Works Association (AWWA) \& Water Environment Federation (WEF). (1998). Standard methods for the examination of water and wastewater (20th Edition). Washington, D.C., EE. UU.: American Public Health Association.

[11] Van Reeuwijk, L.P. (Ed.). (1993). Procedures for soil analysis (4th Edition). Technical paper No. 9. Wageningen, Países Bajos: International Soil Reference and Information Center (ISRIC). 
[12] Guerrero, L. \& Montalvo, S. (2003). Tratamiento anaerobio de residuos. Valparaíso, Chile: Talleres Gráficos Fermín Pastén, p. 413.

[13] Elango, D., Pulikesi, M., Baskaralingam, P., Ramamurthi, V. \& Sivanesan, S. (2007). Production of biogas from municipal solid waste with domestic sewage. Journal of Hazardous Materials, 141 (1), pp. 301-304.

[14] Scaglione, D., Caffaz, S., Ficara, E., Malpei, F. \& Lubello, C. (2008). A simple method to evaluate the short-term biogas yield in anaerobic codigestion of WAS and organic wastes. Water Science \& Technology, 59 (8), pp. 1615-1622.

[15] Akunna, J., Abdullahi, Y. \& Stewart, N. (2007). Anaerobic digestion of municipal solid wastes containing variable proportions of waste types. Water Science \& Technology, 56 (8), pp. 143-149.

[16] PROSAB. (1999). Tratamento de Esgotos Sanitarios por Processo Anaerobio e Disposicao Controlada no solo (Primera Edición). Rio de Janeiro, Brasil: PROSAB, p. 411.

[17] Bouallagui, H., Haouari, O., Touhami, Y., Ben Cheikh, R., Marouani, L. \& Hamdi, M. (2004). Effect of temperature on the performance of an anaerobic tubular reactor treating fruit and vegetable waste. Process Biochemistry, 39, pp. 2143-2148.

[18] Bouallagui, H., Lahdheb, H., Ben Romdan, E., Rachdi, B. \& Hamdi, M. (2009). Improvement of fruit and vegetable waste anaerobic digestion performance and stability with co-substrates addition. Journal of Environmental Management, 90, pp. 1844-1849.

[19] Forster-Carneiro, T., Pérez, M., Romero, L. \& Sales, D. (2007). Dry-thermophilic anaerobic digestion of organic fraction of the municipal solid waste: Focusing on the inoculum sources. Bioresource technology, 98, pp. 3195-3203.

[20] Mohan, S. \& Bindhu, B. (2008). Effect of phase separation on anaerobic digestion of kitchen waste. J. Environ. Eng. Sci. 7, pp. 91-103.

[21] Angelidakia, I., Chen, X. Cui, J., Kaparaju, P. \& Ellegaard, L. (2006). Thermophilic anaerobic digestion of source-sorted organic fraction of household municipal solid waste: Start-up procedure for continuously stirred tank reactor. Water Research, 40, pp. 2621-2628.

[22] Bouallagui, H., Touhami, Y., Ben Cheikh, R. \& Hamdi, M. (2005). Bioreactor performance in anaerobic digestion of fruit and vegetable wastes. Process Biochemistry, 40, pp. 989-995.

[23] Gómez, X., Cuetos, M., Cara, J., Morán, A. \& García, A. (2006). Anaerobic codigestion of primary sludge and the fruit and vegetable fraction of the municipal solid wastes Conditions for mixing and evaluation of the organic loading rate. Renewable Energy, 31, pp. 2017-2024. 